\title{
Fatigue Performance Assessment of Composite Arch Bridge Suspenders Based on Actual Vehicle Loads
}

\author{
Bin Chen, ${ }^{1}$ Xiaozhang Li, ${ }^{1}$ Xu Xie, ${ }^{1}$ Zheng Zhong, ${ }^{2}$ and Pengzhen Lu ${ }^{3}$ \\ ${ }^{1}$ College of Civil Engineering and Architecture, Zhejiang University, Hangzhou 310058, China \\ ${ }^{2}$ Hangzhou Municipal Facilities Supervision and Administration Center, Hangzhou 310003, China \\ ${ }^{3}$ College of Civil Engineering and Architecture, Zhejiang University of Technology, Hangzhou 310003, China
}

Correspondence should be addressed to Xu Xie; xiexu@zju.edu.cn

Received 30 September 2014; Accepted 16 December 2014

Academic Editor: Alicia Gonzalez-Buelga

Copyright (C) 2015 Bin Chen et al. This is an open access article distributed under the Creative Commons Attribution License, which permits unrestricted use, distribution, and reproduction in any medium, provided the original work is properly cited.

\begin{abstract}
In the through arch bridges, the suspenders are the key components connecting the arch rib and the bridge deck in the middle, and their safety is an increasing focus in the field of bridge engineering. In this study, various vehicle traffic flow parameters are investigated based on the actual vehicle data acquired from the long-term structural health monitoring system of a composite arch bridge. The representative vehicle types and the probability density functions of several parameters are determined, including the gross vehicle weight, axle weight, time headway, and speed. A finite element model of the bridge structure is constructed to determine the influence line of the cable force for various suspenders. A simulated vehicle flow, generated using the Monte Carlo method, is applied on the influence lines of the target suspender to determine the stress process, and then the stress amplitude spectrum is obtained based on the statistical analysis of the stress process using the rainflow counting method. The fatigue performance levels of various suspenders are analyzed according to the Palmgren-Miner linear cumulative damage theory, which helps to manage the safety of the suspenders.
\end{abstract}

\section{Introduction}

The development of national economies depends greatly on the effectiveness and reliability of infrastructure systems. In particular, bridges are becoming increasingly important in ensuring the normal operation of transportation networks. Therefore, the smooth running of transportation systems must be facilitated by ensuring the safety of bridge structures. Bridges are affected by cyclic vehicle loads throughout their lifetime, which have uncertain effects on bridge structures. Thus, the fatigue performance of bridge components is very important for resisting vehicle loads [1]. In arch bridges, suspenders are key components that connect the arch rib and the bridge deck in the middle. The dead load and the live load on the bridge deck pass to the arch rib via suspenders. The alternating stress produced by vibration due to vehicles, winds, and earthquakes means that the suspender may suffer fatigue damage in conditions that are far below the static intensity $[2,3]$. Large-span arch bridges may have multiple lanes and the amplitude of the stress variation in the suspender will be greater due to the multilane vehicle loads, which may damage the entire bridge via invalidation of the suspenders. Therefore, the fatigue analysis of suspenders in arch bridges is a major problem, which is being considered increasingly by engineers.

The key aspect of fatigue analysis for suspenders is determining their stress spectrum. Two main methods are used for this purpose: obtaining actual measurements from the bridge and computer-based simulation analysis. Obtaining actual measurement is time consuming and expensive, and the number of points that can be measured is limited. In addition, actual measurements cannot be obtained while a new bridge is being designed. Thus, simulations are used widely. Traffic flow and its load effect are random processes; thus the load effect of vehicle during a time interval is confirmed based on the simulations of this random process. This is the optimal method for confirming the load effect of vehicle based on the simulations of actual traffic data [4-7]. The construction 


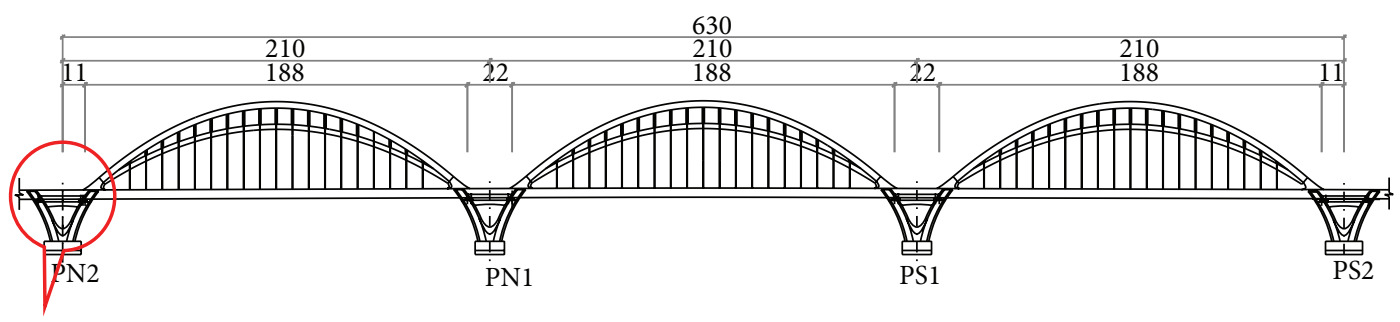

FIGURE 1: Layout of longitudinal section of bridge (m).

of a structure health monitoring system (SHMS) on bridges [8-10] and the widespread application of weigh-in-motion (WIM) systems are very helpful for obtaining more actual traffic data and for developing traffic load models based on the WIM data [11-15]. Using the WIM data, the traffic load effect can be calculated accurately, thereby allowing the prediction of the future load traffic effect and its effect on bridge performance using relevant theory [16-19].

In this study, based on the vehicle load acquisition system in the SHMS of a large-span composite arch bridge, the traffic flow data and a series of traffic flow parameters are obtained, including the vehicle type classification, gross vehicle weight, axle weight, time headway, speed, and transverse distribution of the traffic flow, which are subjected to a statistical analysis. Using the actual statistical parameters measured from a random traffic flow and based on the Monte Carlo method, the bidirectional and multilane random traffic flow is simulated using a FORTRAN program. The influence line of an objective suspender is loaded through the random traffic flow loads to obtain the suspender stress process and the stress spectrum is then obtained using the rainflow counting method. Finally, a suitable $S-N$ curve for the bridge suspender is selected and the fatigue condition of the suspender is analyzed using the Palmgren-Miner linear fatigue cumulative damage criterion.

\section{Bridge and SHMS}

2.1. Bridge Description. The full length of the objective bridge is $1,855 \mathrm{~m}$. The upper structure of the main bridge comprises a $3 \times 210 \mathrm{~m}$ arch bridge (Figure 1). The arch rib system comprises the main arch ribs, vice arch ribs, transverse connecting rods between the main and vice arch ribs, and the lateral braces of the vault. The main beam of the arch bridge is a constant section with a steel-concrete composite beam structure. The composite beam is a double-girder system with a main longitudinal girder, medial horizontal beam, end horizontal beam, and small longitudinal girder. The full height and full width of the composite beam are $4.5 \mathrm{~m}$ and $37.7 \mathrm{~m}$, respectively. The space between the main longitudinal steel girders on both sides is $27.6 \mathrm{~m}$, the space between the horizontal steel beams is $4.25 \mathrm{~m}$, and the thickness of the concrete bridge deck is $26 \mathrm{~cm}$. Tie bars are set inside the longitudinal main steel girder. The space between the suspenders along the arch bridge is $8.5 \mathrm{~m}$. The upper and lower ends of the suspenders are anchored in the main arch rib and the main longitudinal steel girder, respectively. Each suspending point is a single suspender and there are 114 suspenders on the whole bridge.

2.2. Structure Health Monitoring System. The structure health monitoring system (SHMS) installed on the objective bridge comprises a data acquisition and monitoring subsystem (DAMS), inspection and maintenance subsystem (IMS), data storage and management subsystem (DSMS), warning and safety assessment subsystem (WSAS), and user interface subsystem (UIS). The DAMS mainly determines the load source and the structural response. The load sources include the wind load, temperature, vehicle load, and seismic activity. The structural responses include the stress of the steel structure and concrete structure, specific deflection of the bridge, variation in the cable force (including the cable force of sling, the cable force of the tie bar of the main bridge, and the cable force of the external cable on the approach bridge), and the vibration response of the structure (including vibration monitoring of the main arch and main beam). The SHMS comprises 347 sensors. The vehicle load acquisition equipment (Figure 2) can collect many types of information from vehicles that pass over the observed sections, such as the vehicle speed, direction, license plate number, vehicle type, passing time, axle weight, and the gross vehicle weight, which can greatly improve the efficiency and precision of traffic load surveys. Thus, based on the traffic information monitoring and by reconstructing the traffic flow in simulations, the stress variation and the fatigue characteristic of the bridge suspenders under the actual vehicle loads can be analyzed in the present study.

\section{Survey of Traffic Conditions}

Traffic flow data are acquired for 18 months after the SHMS has been installed and put into operation. These data fully reflected the actual conditions of the traffic loads. During the analysis, some erroneous data are removed to ensure that the data reflected the true conditions of the traffic loads. In addition, by referring to the UK standards, vehicles weighing $\geq 3$ tons are classified as trucks and the effect of cars on the bridge fatigue characteristics is omitted.

3.1. Traffic Flow Characteristics. Traffic flow can be divided into daily traffic and hourly traffic. The daily traffic represents the variation in the daily traffic flow during a week and the hourly traffic represents the variation in the traffic flow at each 

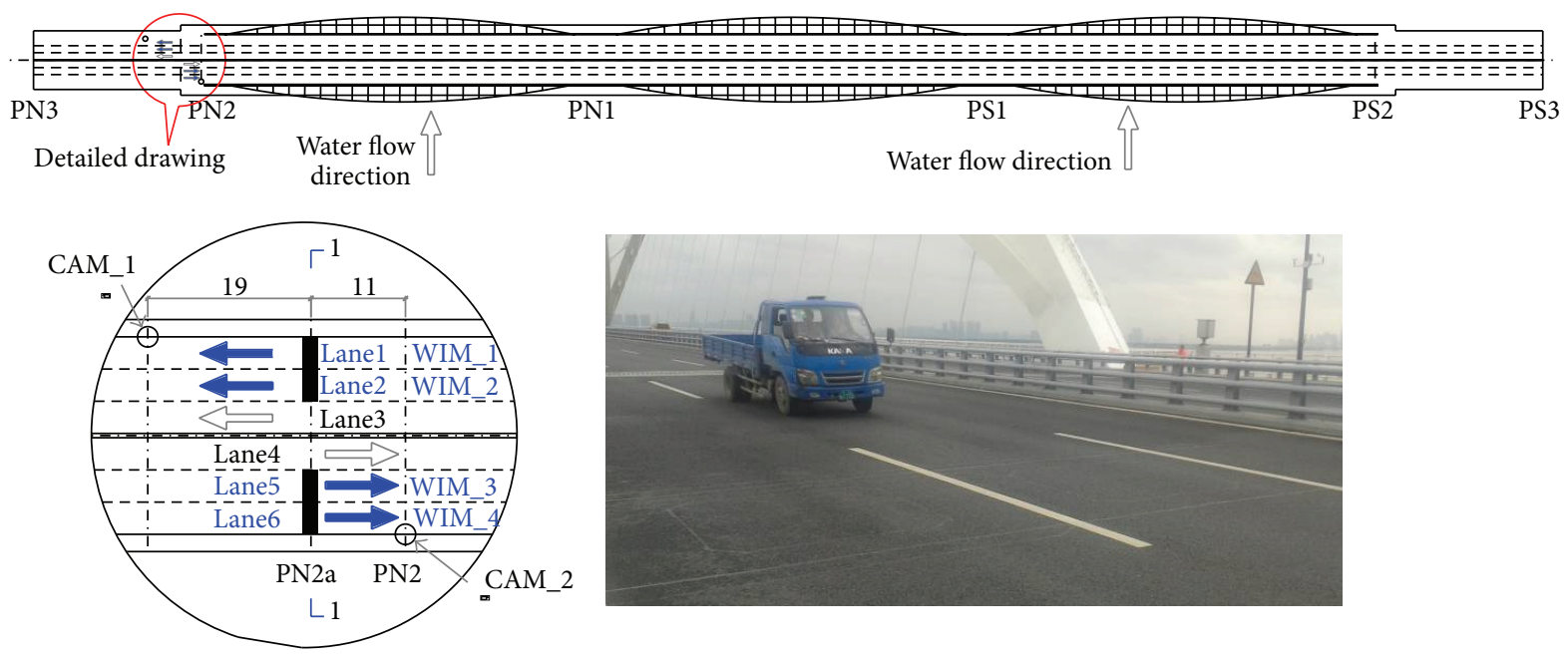

FIGURE 2: Installation positions of vehicle load acquisition system on bridge.

TABLe 1: Traffic flow distributions for vehicles with different axle numbers during two weeks.

\begin{tabular}{lccccc}
\hline Axle number & 2 & 3 & 4 & 5 & 6 \\
\hline First week & 183173 & 2057 & 1358 & 396 & 382 \\
Second week & 145413 & 1602 & 907 & 228 & 259 \\
\hline
\end{tabular}

time of day. Thus, it is reasonable to combine both to analyze the variation in the actual traffic flow. Figure 3 shows that the overall distribution of the daily traffic flow declined from Monday to Sunday over a two-week period. In addition, there are major differences in the daily traffic flow between the first week and the second week, where the maximum daily traffic is ca 32,000 in the first week but only 24,000 in the second week. Furthermore, the total traffic flow had a regular pattern at each time of the day (Figure 4), with a peak at about 09:00, a second peak at about 18:00, and a maximum traffic flow per time interval of ca 2700. Based on the distribution of the traffic flow, two-axle vehicles comprised $97.7 \%$ of the total and the vehicle number decreased with the axle number (Table 1).

3.2. Types of Trucks. The effect of small vehicles on bridge performance is very low; thus only trucks are considered in studies of vehicle types and their distributions. Based on the axle space and axle type characteristics determined from the data, the trucks are classified as typical vehicle types. Tables 2 and 3 present the axle weight and axle space data. Some vehicles are removed during the classification and extraction of the vehicle types, such as vehicles with seven axles or more, due to measurement errors and illegal modifications. The results of the vehicle type analysis show that trucks accounted for $19.52 \%$ of the total traffic flow, where two-axle heavy trucks and two-axle large buses comprised a high percentage, thereby reflecting the typical characteristics of urban road traffic.

3.3. Gross Vehicle Weight. Different vehicle types have various effects on bridges because of the differences in vehicle

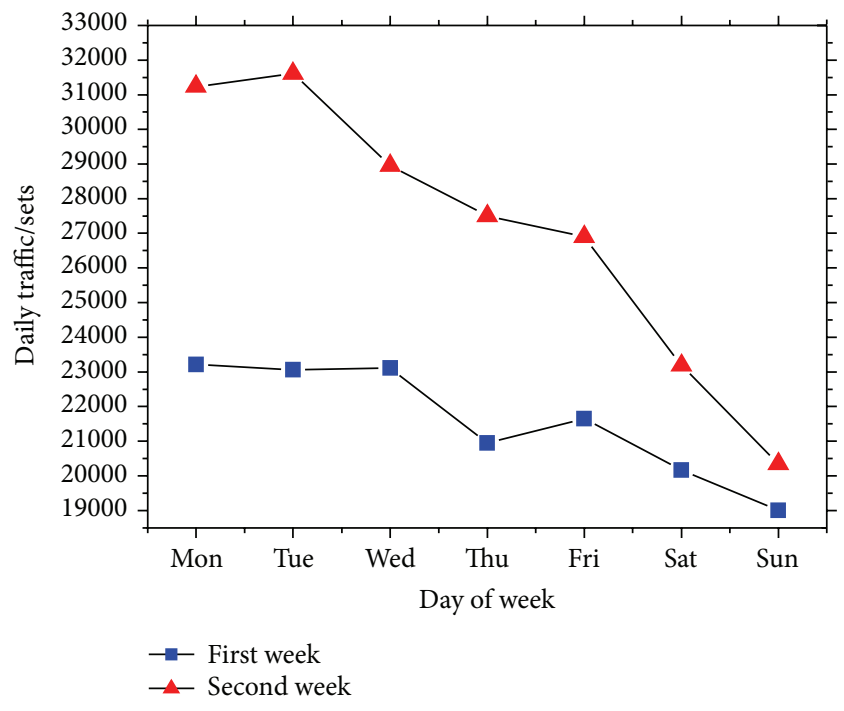

Figure 3: Daily traffic flow.

construction and their weight. According to the vehicle type classifications, the probability distribution patterns for the gross vehicle weights of different vehicle types are determined, thereby providing the basis for precise simulations of the measured traffic flow. Other studies have shown that the traffic load may comprise no loads, half loads, and full loads, and the gross vehicle weight probability distribution has a multimodal distribution [20-23], which can be viewed as a linear combination of different probability distributions. Suppose that the probability density function of the $i$ th vehicle load is $f_{X}(x)$. The probability densities of $n$ traffic loads are combined linearly and the probability density function of the traffic load can then be expressed as

$$
f_{X}(x)=\sum_{i=1}^{n} p_{i} f_{i}(x)
$$


TABLE 2: Vehicle classification and axle weight statistics.

\begin{tabular}{|c|c|c|c|c|c|c|c|c|}
\hline \multicolumn{3}{|c|}{ Vehicle classification } & \multicolumn{6}{|c|}{ Average value and deviation of axle weight $(t)$} \\
\hline Vehicle type & Axle diagram & Ratio & Axle 1 & Axle 2 & Axle 3 & Axle 4 & Axle 5 & Axle 6 \\
\hline V21 & & $1.71 \%$ & $(1.89,0.54)$ & $(2.30,1.80)$ & & & & \\
\hline V22 & $\sigma$ & $8.81 \%$ & $(3.40,1.55)$ & $(7.74,6.57)$ & & & & \\
\hline V23 & & $5.91 \%$ & $(5.05,1.33)$ & $(9.84,3.30)$ & & & & \\
\hline V31 & 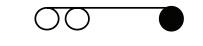 & $0.54 \%$ & $(4.36,1.42)$ & $(4.48,2.15)$ & $(1.37,7.17)$ & & & \\
\hline V32 & $\sigma$ & $0.60 \%$ & $(7.68,3.26)$ & $(13.66,9.08)$ & $(13.74,9.50)$ & & & \\
\hline V41 & 00 & $0.90 \%$ & $(6.85,3.18)$ & $(7.44,3.50)$ & $(13.97,9.67)$ & $(15.25,9.15)$ & & \\
\hline V42 & $\sigma$ & $0.36 \%$ & $(4.10,0.76)$ & $(12.03,4.29)$ & $(11.96,4.79)$ & $(11.87,4.65)$ & & \\
\hline V51 & 0 & $0.34 \%$ & $(5.55,1.24)$ & $(12.53,4.61)$ & $(11.47,4.56)$ & $(10.75,4.16)$ & $(11.23,4.17)$ & \\
\hline V61 & 000 & $0.20 \%$ & $(4.24,0.61)$ & $(4.40,1.35)$ & $(11.29,4.99)$ & $(9.61,4.95)$ & $(9.71,4.75)$ & $(10.49,5.19)$ \\
\hline V62 & 0 & $0.15 \%$ & $(5.59,0.88)$ & $(8.42,3.80)$ & $(7.98,3.57)$ & $(9.59,5.59)$ & $(9.24,5.18)$ & $(10.30,5.54)$ \\
\hline
\end{tabular}

TABLE 3: Vehicle classification and axle space statistics.

\begin{tabular}{|c|c|c|c|c|c|c|c|}
\hline \multicolumn{3}{|c|}{ Vehicle classification } & \multicolumn{5}{|c|}{ Average value and deviation of axle space $(\mathrm{m})$} \\
\hline Vehicle type & Axle diagram & Ratio & Axle 1 & Axle 2 & Axle 3 & Axle 4 & Axle 5 \\
\hline V21 & & $1.71 \%$ & $(2.98,0.35)$ & & & & \\
\hline V22 & $\sigma$ & $8.81 \%$ & $(4.72,0.73)$ & & & & \\
\hline V23 & & $5.91 \%$ & $(6.64,0.84)$ & & & & \\
\hline V31 & 00 & $0.54 \%$ & $(2.10,0.74)$ & $(5.75,1.27)$ & & & \\
\hline V32 & $\sigma$ & $0.60 \%$ & $(5.07,1.40)$ & $(1.54,0.58)$ & & & \\
\hline V41 & 00 & $0.90 \%$ & $(2.02,0.52)$ & $(4.76,0.99)$ & $(1.41,0.25)$ & & \\
\hline V42 & $\bigcirc 0$ & $0.36 \%$ & $(3.80,0.39)$ & $(6.83,1.01)$ & $(1.37,0.10)$ & & \\
\hline V51 & 00 & $0.34 \%$ & $(3.73,0.76)$ & $(6.60,1.40)$ & $(1.43,0.70)$ & $(1.35,0.25)$ & \\
\hline V61 & 000 & $0.20 \%$ & $(1.93,0.34)$ & $(2.74,0.52)$ & $(6.56,1.37)$ & $(1.37,0.21)$ & $(1.37,0.22)$ \\
\hline V62 & 00 & $0.15 \%$ & $(3.48,0.55)$ & $(1.46,0.22)$ & $(6.97,1.72)$ & $(1.39,0.21)$ & $(1.38,0.21)$ \\
\hline
\end{tabular}

where $\sum_{i=1}^{n} p_{i}=1$. In general, the form of the above probability density function $f_{i}(x)$ can differ, which can be determined according to the fit of the measured vehicle loads. In the present study, $f_{i}(x)$ has the same form as probability density functions such as the normal distribution and lognormal distribution, but the statistical parameters are different. The parameters are estimated using the most common and the effective expectation maximum (EM) algorithm. Previous studies have shown that satisfactory results can be obtained using the EM algorithm for parameter estimation in mixed distribution models [24]. In our study, we fitted mixed distribution functions with different probability distributions to the gross vehicle weights of different vehicle types using the Kolmogorov-Smirnov $(K-S)$ test as a goodness of fit test for the cumulative distribution function. The best results were obtained using a third-order mixed log-normal distribution to fit two-axle vehicles and a third-order mixed normal distribution to fit three-axle, four-axle, five-axle, and six-axle vehicles (Figure 5). In particular, the good fit of the mixed model probability distribution to the tail distribution avoided the poor results obtained when using first-order and secondorder mixed model distributions for fitting. Table 4 shows the parameters of the probability distributions for various vehicle types. The gross weight distribution shows that the trucks mostly had no loads, full loads, and overloads, although very few had half loads in this study.

3.4. Axle Weights of Vehicle. Previous studies have shown that coaches and trucks with two axles and more than four wheels cause the most structural damage to bridges and roads, whereas little damage is caused by other trucks [25]. Trucks with two axles and more than four wheels can be classified as whole vehicles, semitrailers, and full trailers. According to the vehicle type database, the common axle types of vehicle can be classified as one axle, two axles, and three axles, and the common wheel types can be classified as single wheel and double wheel. By combining these vehicle types, the following common combinations of axle and wheel types can be obtained: one axle and single wheel (A1), one axle and double wheel (A2), two axle and double wheel (A3), and three axle and double wheel (A4) (Figure 6).

To further understand the vehicle load patterns, the relationships between the GVW and the axle weights of various vehicle types are analyzed using scatter plots, with the gross weight on the $x$-axis and the axle load and axle group weight on the $y$-axis. The scatter plot data are then fitted by a linear regression. The results show that the relationship between the gross vehicle weight and the axle load is linear 
TABLE 4: Parameters of the mixed probability distribution for GVW.

\begin{tabular}{lcccccccccc}
\hline \multirow{2}{*}{ Truck type } & Distribution type & \multicolumn{3}{c}{ First distribution } & \multicolumn{3}{c}{ Second distribution } & \multicolumn{3}{c}{ Third distribution } \\
& & $t$ & $u$ & sig & $t$ & $u$ & sig & $t$ & $u$ \\
\hline V21 & Lognormal & 0.35 & 1.14 & 0.04 & 0.46 & 1.32 & 0.12 & 0.19 & 1.87 & 0.42 \\
V22 & Lognormal & 0.20 & 1.26 & 0.12 & 0.76 & 2.37 & 0.52 & 0.04 & 3.43 & 0.14 \\
V23 & Lognormal & 0.15 & 2.18 & 0.41 & 0.83 & 2.73 & 0.17 & 0.02 & 3.36 & 0.23 \\
V31 & Normal & 0.54 & 12.56 & 3.16 & 0.43 & 25.52 & 7.16 & 0.03 & 47.15 & 8.44 \\
V32 & Normal & 0.45 & 16.80 & 4.86 & 0.27 & 35.11 & 7.23 & 0.27 & 65.16 & 10.11 \\
V41 & Normal & 0.16 & 14.29 & 1.47 & 0.58 & 35.97 & 12.86 & 0.26 & 77.78 & 6.72 \\
V42 & Normal & 0.12 & 13.68 & 1.19 & 0.63 & 44.90 & 7.24 & 0.26 & 39.92 & 13.46 \\
V51 & Normal & 0.12 & 17.32 & 1.96 & 0.83 & 54.81 & 11.11 & 0.05 & 74.25 & 11.02 \\
V61 & Normal & 0.19 & 17.71 & 1.63 & 0.80 & 56.85 & 12.98 & 0.01 & 100.61 & 3.41 \\
V62 & Normal & 0.26 & 20.22 & 2.68 & 0.72 & 61.27 & 14.87 & 0.01 & 117.69 & 5.87 \\
\hline
\end{tabular}

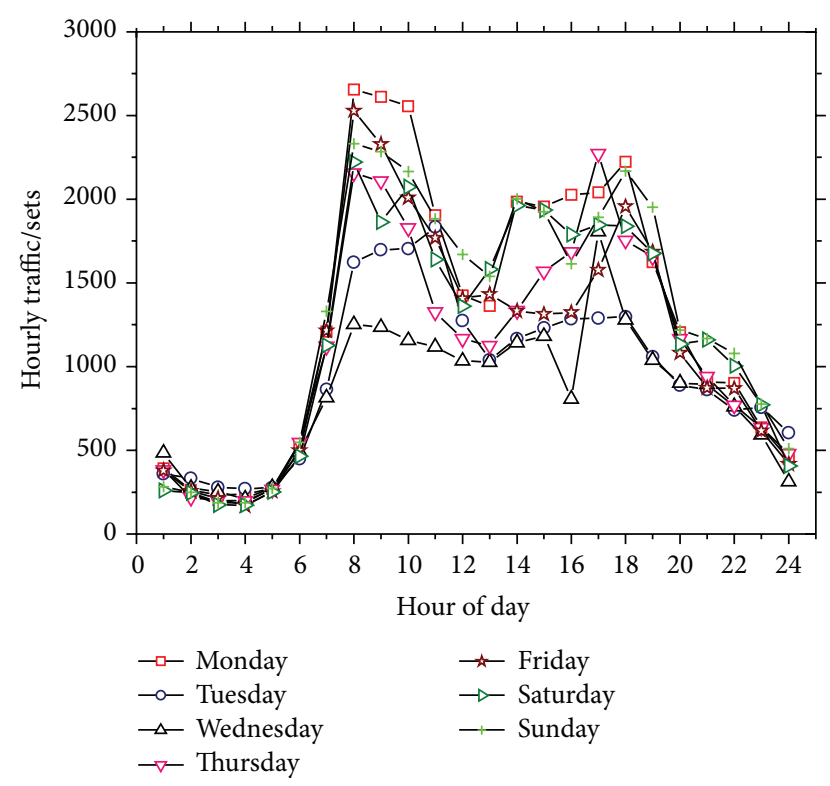

Figure 4: Hourly traffic flow.

(Figure 7). In Figure 8, the two front axles (A1 and A2) of V31 and V41 are one axle and single wheel, and their distribution patterns are the same; thus the same straight line is fitted. The results showed that the linear relationship between the axle load and the gross weight is not absolute and it is related to the vehicle type. When the vehicle type is omitted, the linear relationship is changed or disappears.

3.5. Headway and Speed. The movement of vehicles traveling on roads can be classified into free flow and following flow. When the movement of a vehicle is not affected by the vehicles moving in front, it can be referred to as free flow, but otherwise it is known as following flow. According to a study of the traffic load code used in Chinese highway bridge design, the headways for the free flow state and following flow state follow Gamma distributions based on actual measurement data [28]. Other studies have shown that the traffic loads of medium and small span bridges are controlled by free flows whereas those of large-span bridges are controlled by following flows [29-31]. According to the variation in the traffic flow during a day, the headway that vehicles travel during one day is classified into free flow and following flow according to different time intervals, where the free flow occurs at time intervals with a low density of traffic flow, that is, 00:00-05:00 and 22:00-24:00, and the following flow occurs at time intervals with a high density of traffic flow, that is, 08:00-11:00 and 14:00-18:00, while the headway characteristics of other time intervals vary between the free flow and the following flow. From the headway results obtained in the present study, the maximum is $1,200 \mathrm{~s}$ but most of the headways were $<3 \mathrm{~s}$; thus the range of the distribution is relatively wide. In practical applications of traffic loads, the superposition of the load effects of two adjacent vehicles is meaningless after the headway exceeds a specific level. Therefore, a time headway distribution pattern of $<50 \mathrm{~s}$ is considered in the present study. Various probability distributions such as the negative exponential distribution, shifted negative exponential distribution, Erlang distribution, M3 distribution, Weibull distribution, log-normal distribution, and Gamma distribution are used for fitting and the $K$ $S$ test which is used for the goodness of fit test. The results show that the time headway of the following flows followed a log-normal distribution and the time headway of free flows followed a Gamma distribution, as shown in Table 5.

Vehicle speed is an important parameter that determines the start and end position of a vehicle in the traffic flow and it is also an important factor for determining the load effect of traffic. Different speeds produce variable effects when the same vehicles pass over a bridge. Thus, it is necessary to determine the vehicle speed distribution patterns based on the actual data so the effect of vehicle speed can be considered when simulating the traffic flow and analyzing the load effect of the traffic flow. Figure 8 shows the analysis of the actual vehicle speed data, which demonstrates that the vehicle speed followed a normal distribution, and the specific parameters are shown in Table 6. 


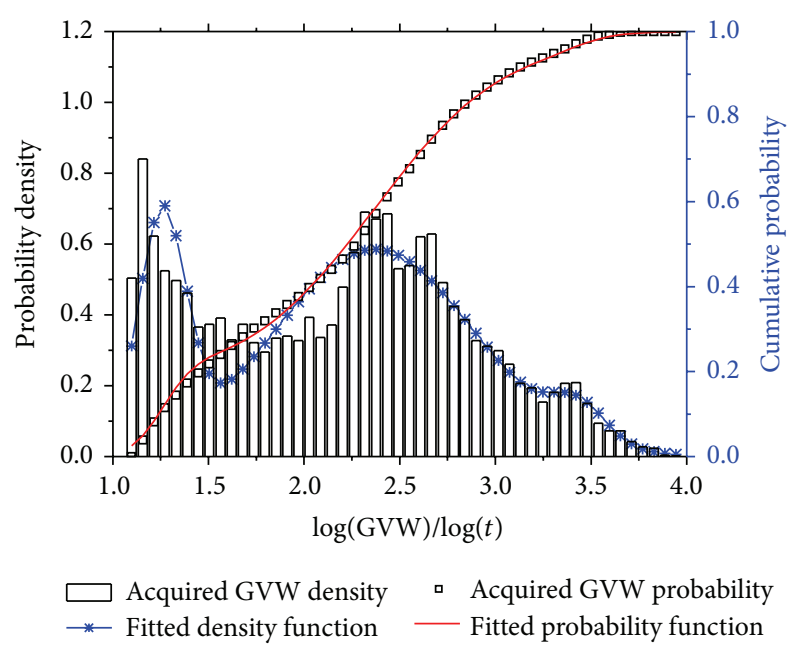

(a) V22
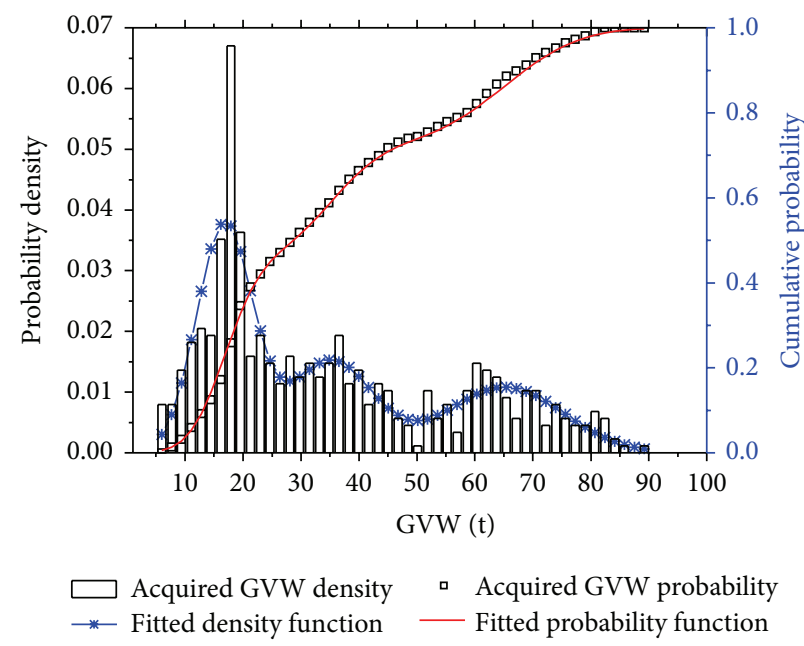

(c) V32

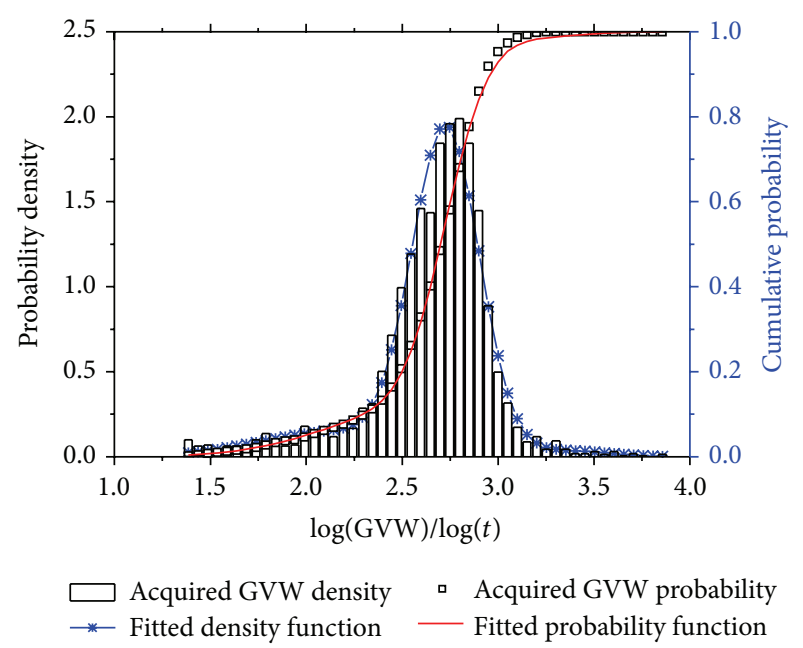

(b) V23

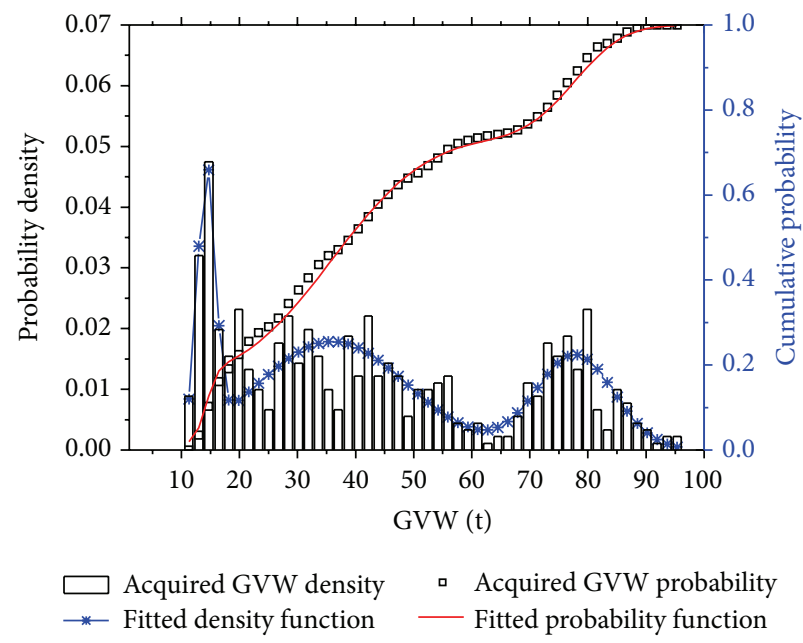

(d) V41

FIGURE 5: Probability distribution of GVW for different truck types.

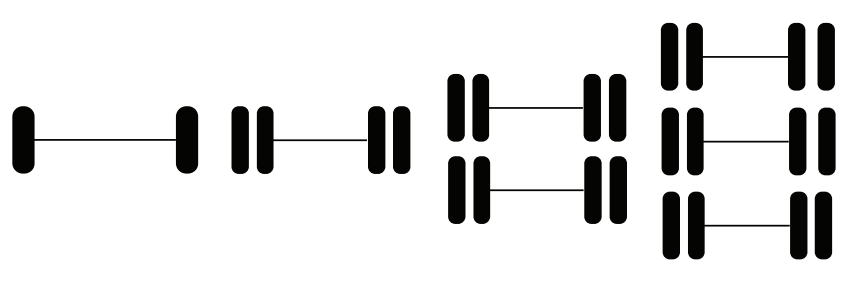

A1
A3

A4

FIGURE 6: Common axle types [26, 27].

3.6. Transverse Distribution of the Traffic Flow. The transverse distribution of vehicle loads is an important factor that determines the load effect of vehicles [12]. In the design standards of bridges in China, the transverse distribution of a vehicle is considered in a load layout with respect to the most adverse positions in the transverse direction using the multilane transverse distribution coefficient to

TABle 5: Probability distribution types and parameters for the headways.

\begin{tabular}{lccc}
\hline Headway & Distribution type & $\alpha$ & $\beta$ \\
\hline Lane 1 & Gamma & 1.85 & 10.75 \\
$\quad$ Free flow & log-normal & 1.56 & 0.878 \\
Following flow & & & \\
Lane 2 & Gamma & 1.38 & 8.74 \\
Free flow & log-normal & 0.83 & 0.58 \\
Following flow & & & \\
\hline
\end{tabular}

account for the load effect, where this coefficient is studied under the hypothesis that vehicle loads are uncorrelated in various lanes [12]. However, previous studies have shown that different vehicle types all occupied their usual lanes when actual vehicles are considered and the traffic flow compositions generally differed among lanes [12]. Table 7 

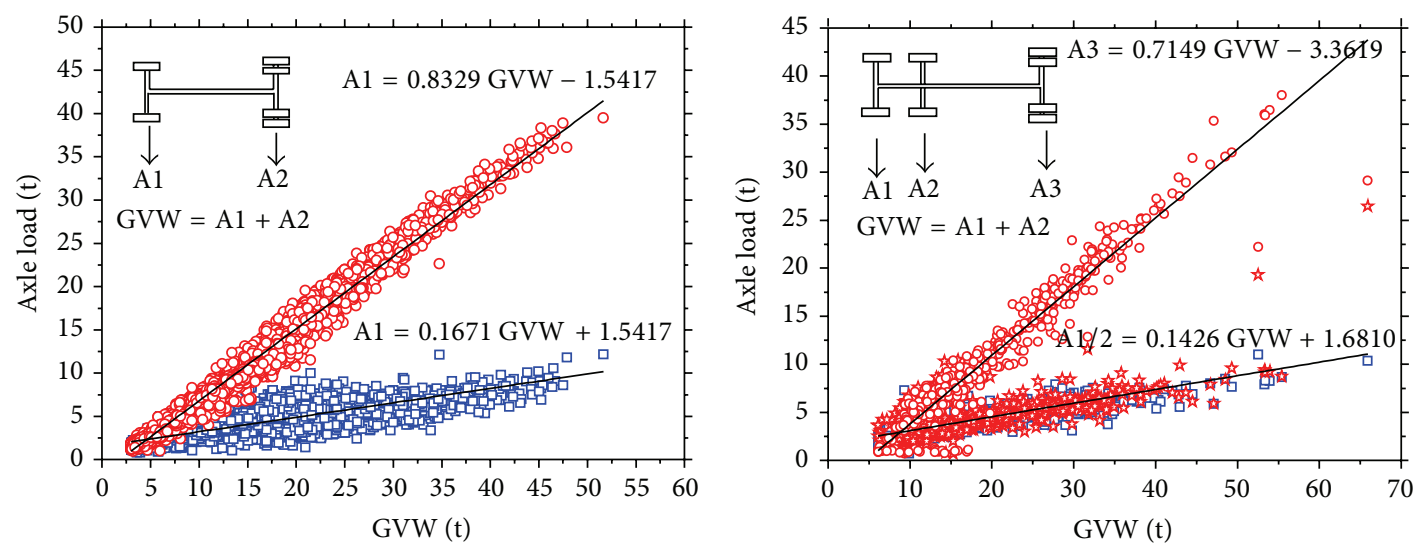

$\square \mathrm{A} 1$

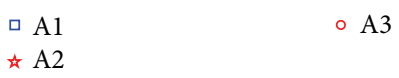

(a) V22

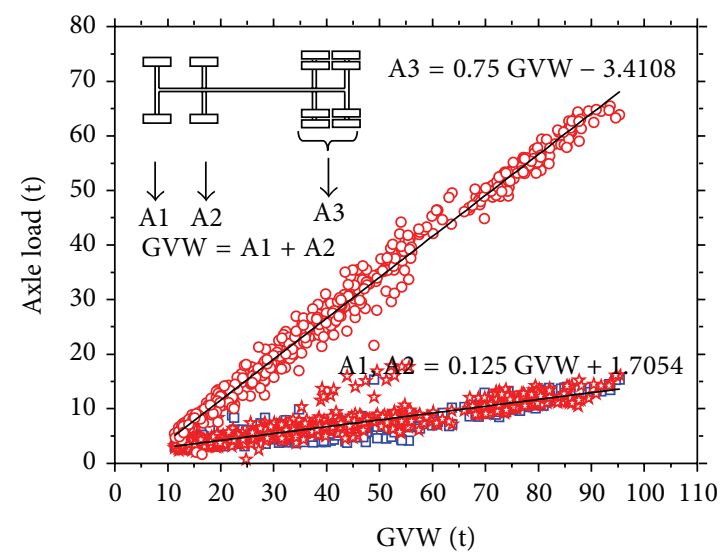

(b) V31
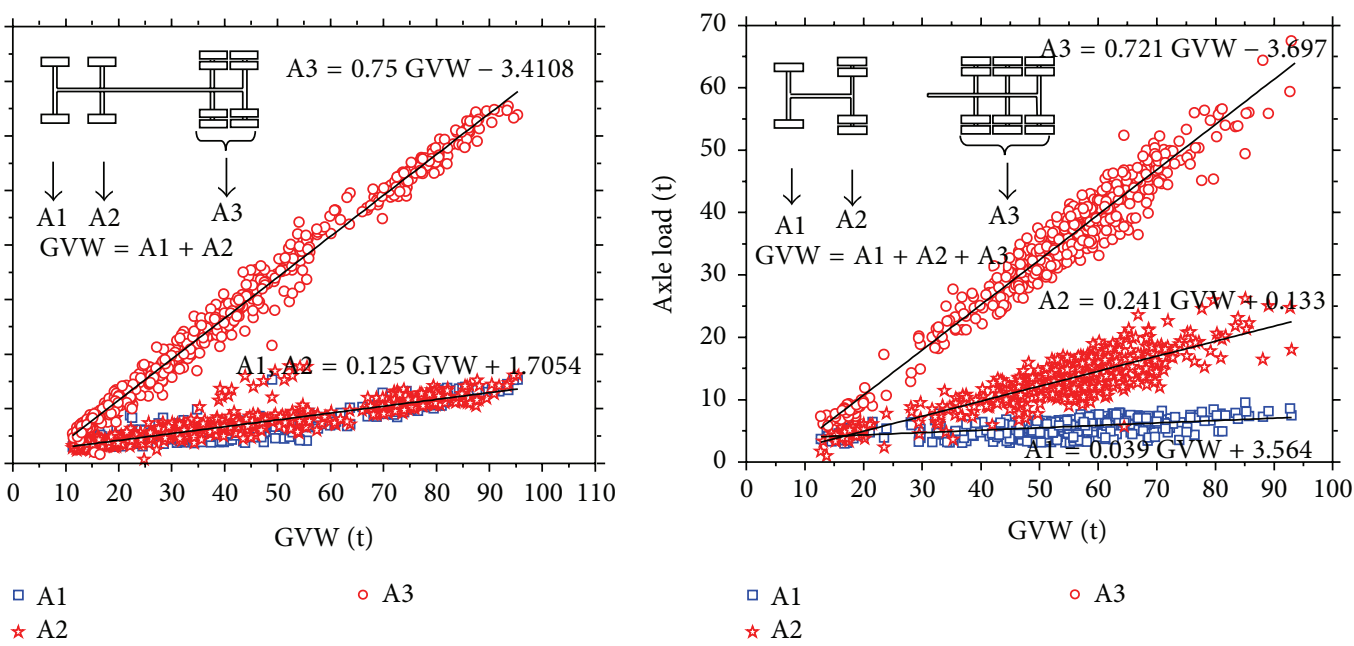

$\square$ A1

- A3

(c) V41

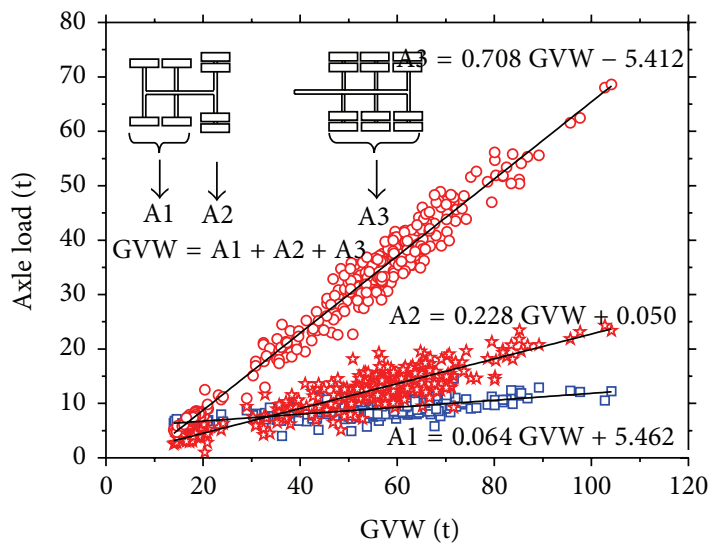

(d) V51

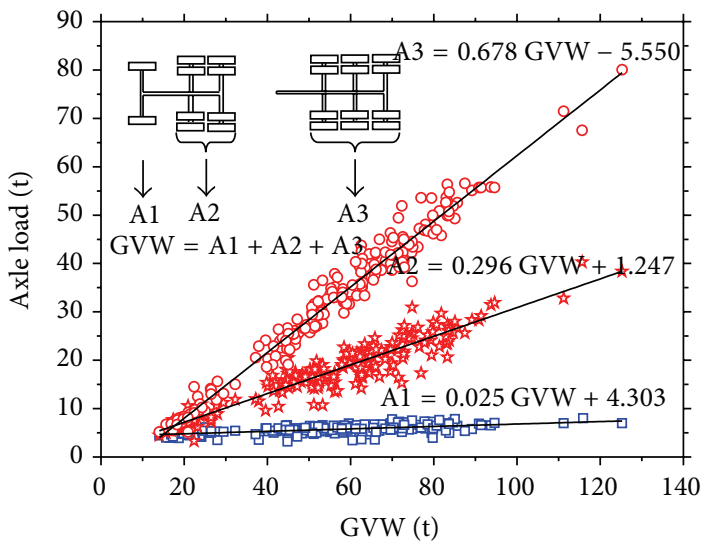

$\square \mathrm{A} 1$
$\leftarrow \mathrm{A} 2$

$\circ \mathrm{A} 3$

$\square \mathrm{A} 1$

- A3

« A2

(e) V61

(f) V62

FIGURE 7: Relationships between GVW and axle weights of various vehicle types. 


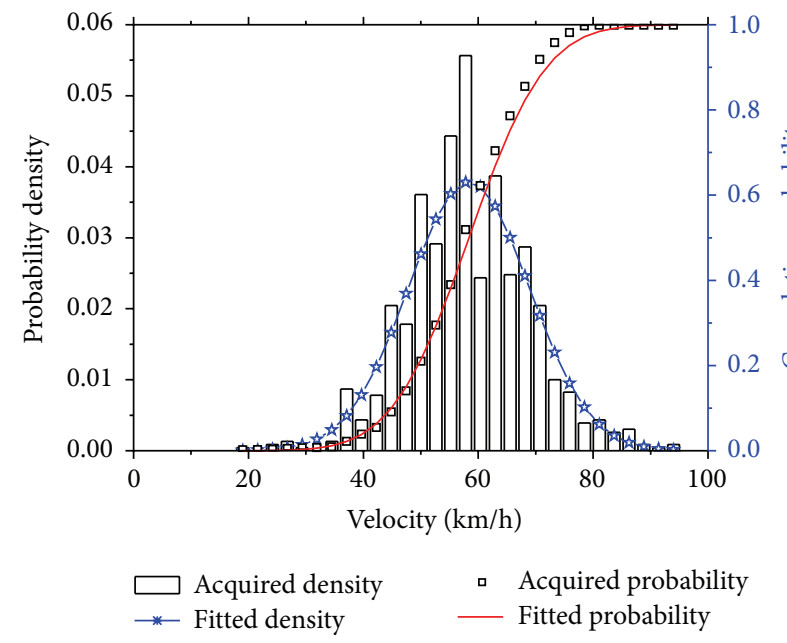

(a) Free flow

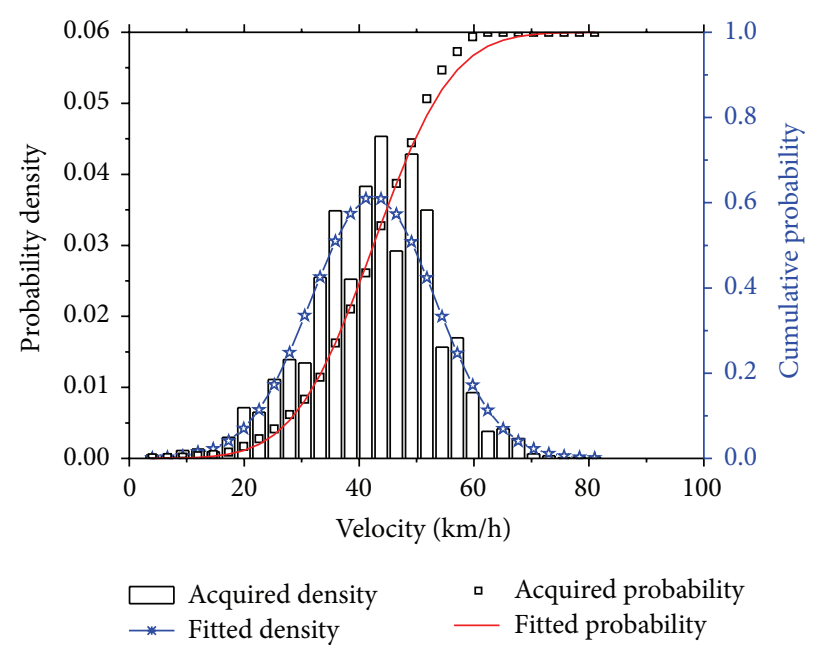

(b) Following flow

Figure 8: Probability distributions for speed with different flow states.

TABle 6: Parameters of the Gaussian distribution for speed with different flow states.

\begin{tabular}{lcccc}
\hline \multirow{2}{*}{ State } & \multicolumn{2}{c}{ Lane 1 } & \multicolumn{2}{c}{ Lane 2 } \\
& $\mu$ & $\sigma$ & $\mu$ & $\sigma$ \\
\hline Free flow & 54.68 & 16.23 & 58.12 & 10.75 \\
Following flow & 45.86 & 19.20 & 45.02 & 9.23 \\
\hline
\end{tabular}

TABLE 7: Transverse distribution of the traffic flow.

\begin{tabular}{lccccccccccc}
\hline $\begin{array}{l}\text { Axle } \\
\text { number }\end{array}$ & V21 & V22 & V23 & V31 & V32 & V41 & V42 & V51 & V61 & V62 \\
\hline Lane 1 & 0.60 & 0.23 & 0.09 & 0.02 & 0.01 & 0.02 & 0.01 & 0.02 & 0.01 & 0.01 \\
Lane 2 & 0.54 & 0.21 & 0.08 & 0.01 & 0.01 & 0.01 & 0.01 & 0.01 & 0.01 & 0.01 \\
\hline
\end{tabular}

shows the transverse distribution for various vehicle types in two lanes.

\section{Analysis of Stress Variation}

To analyze the fatigue life of suspenders, the stress spectrum of suspenders must first be obtained. Acquiring actual measurements is the most direct method for obtaining the stress spectrum of suspenders, where the measurement points are positioned along the suspender to allow dynamic sampling and long-term monitoring of the stress process. However, the cost of obtaining actual measurements is very high and the process is time consuming, while the stress sampling process is limited. Given these many adverse factors, a computer-based simulation analysis method is developed in this study. First, a spatial finite element model of the bridge is constructed to obtain the influence line of the internal force of a suspender. Second, using the actual statistical parameters of the random traffic flow derived from measurements and based on the Monte Carlo method, random traffic flows traveling in multiple lanes in either direction are simulated

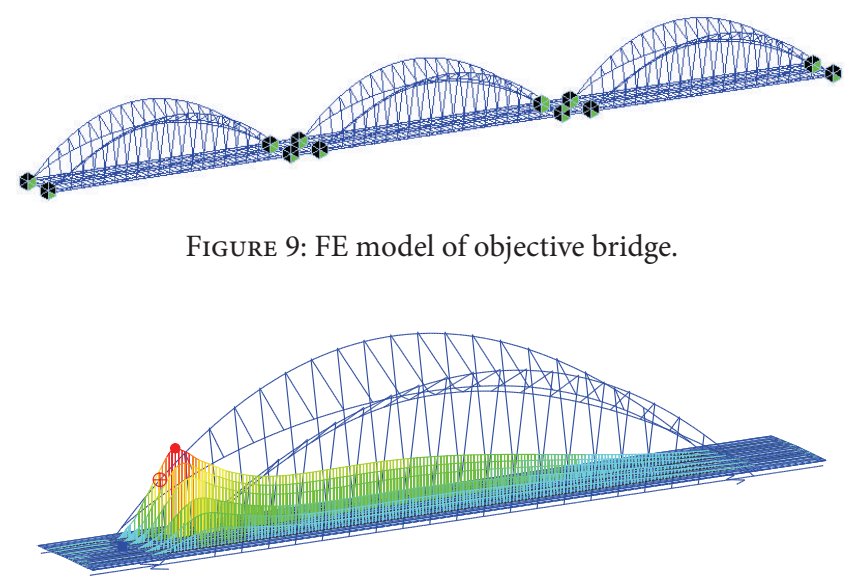

FIGURE 10: Influence line of shortest suspender.

with a FORTRAN program. Third, the influence line of the objective suspender is loaded to obtain the stress process for the suspender and the stress spectrum is then obtained via the cyclic statistics of the stress process. Finally, the fatigue condition of the suspender is analyzed by selecting a suitable $S-N$ curve for the suspenders using the Palmgren-Miner linear fatigue cumulative damage criterion.

4.1. Finite Element (FE) Model. In this study, the Midas software is used to build a spatial model of the objective bridge. Figure 9 shows the FE model. The elements and quantities used for structural modeling are shown in Table 8.

The shortest suspender on the side of the midspan is selected as the subject of the analysis and its influence line is extracted for a lane. Figure 10 shows the influence line.

4.2. Traffic Simulation. The actual traffic situation is very complex, where the difference in vehicle types is great and 
TABLE 8: Element types and numbers in FE model.

\begin{tabular}{lcc}
\hline Substructure & Element type & Element number \\
\hline Main arch & Beam & 132 \\
Vice arch & Beam & 120 \\
Suspender & $\begin{array}{c}\text { Elements only } \\
\text { tensioned }\end{array}$ & 130 \\
Main longitudinal girder & Beam & 414 \\
Vice longitudinal girder & Beam & 284 \\
Transverse girder & Beam & 572 \\
Tie bar cable & Elements only & 16 \\
Transverse bracing & tensioned & 9 \\
Connecting rod & Beam & 102
\end{tabular}

complex traffic conditions may occur such as traffic jams and overtaking. If a random traffic flow is simulated faithfully according to the actual situation, this requires a considerable amount of programming work and the arithmetic speed is also restricted by the computer's performance. In the present study, the effects of complex traffic conditions, such as traffic jams and overtaking, on the fatigue analysis are not considered. Therefore, when simulating the traffic loads, following travel is assumed and there are no traffic jams or overtaking. The traffic flow in self-lanes is independent. Some parameters, such as the headway, vehicle type, GVW, and axle space, are uncorrelated random variables that followed the measured distributions. The steps employed to produce the random traffic flow are as follows.

(1) According to the following flow parameters for different lanes, a log-normal distribution is sampled to obtain the time headway, which is then converted into the distance headway according to the vehicle speed.

(2) According to the actual ratio of vehicle types, a uniform distribution is sampled to obtain the vehicle types.

(3) According to the actual distributions of different vehicle types, a multimodal normal distribution or a log-normal distribution is sampled to obtain the GVW. The axle load is obtained according to the fitted relationship between the GVW and the axle weight.

(4) According to the actual axle spaces of different vehicle types, a uniform distribution is sampled to obtain the axle space. And the total vehicle length is calculated.

(5) If the traffic flow time is less than the assumed value, step (1) is repeated. If the spacing of the next vehicle is less than the total length of the previous vehicle, the total length of the previous vehicle will replace the spacing.

According to these steps, the random traffic flow used for fatigue analysis is produced automatically in the FORTRAN language. Figure 11 shows a flow diagram of the program.

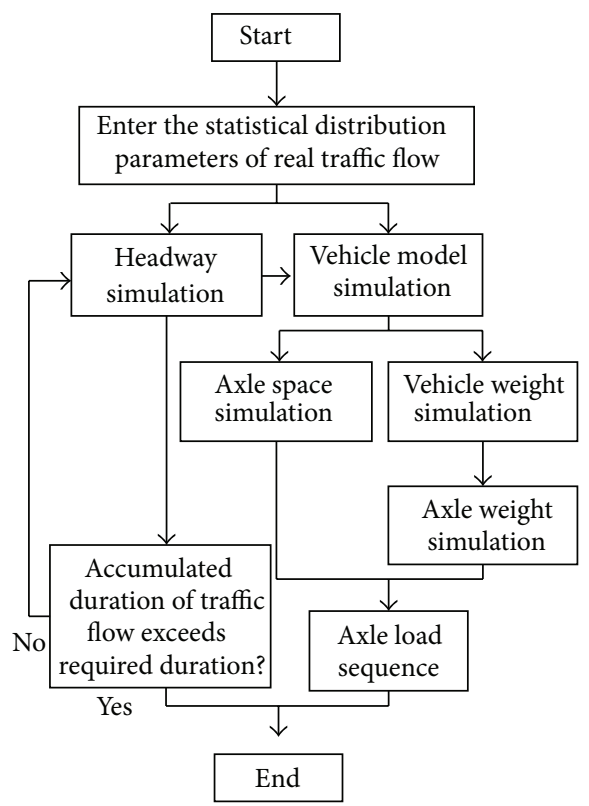

FIGURE 11: Flowchart of random traffic flow simulation program.

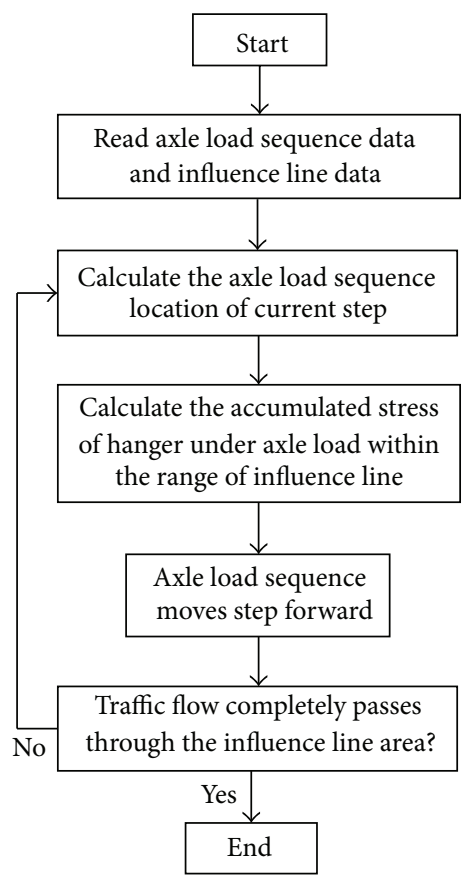

FIGURE 12: Flowchart showing calculation of suspender stress.

4.3. Stress Process and Stress Spectrum of Suspender. The random traffic flow moves across the bridge step by step. At each load step, all of the load responses of the axle load within the range of the influence line are superposed to obtain the total response value of the suspender stress in the current step. The fatigue stress process of the suspender is obtained after the vehicle passed over the bridge. The stress process is also calculated using the FORTRAN language. Figure 12 shows the flowchart of the program. 
The stress process refers to the variation in stress during a time interval. The stress spectrum of fatigue is obtained using the statistics from the stress process. Many statistical methods can be used to analyze the stress process. In this study, the rainflow counting method is used.

4.4. Calculation of Fatigue Damage. At present, it is still uncertain which method is the most reasonable for analyzing cyclic loading to determine the cumulative damage to a structure. The linear fatigue cumulative damage theory of Palmgren and Miner is generally used in fatigue analysis of bridge structures [32]. The fatigue damage degree of a component defined by the Miner criterion under variable amplitude loads is

$$
D=\sum_{i=1}^{k} \frac{n_{i}}{N_{i}}
$$

where $n_{i}$ is the time of the stress amplitude $\Delta \sigma_{i}, N_{i}$ is the time of fatigue failure in a cyclic test, and $\Delta \sigma_{i}$ is a constant amplitude stress, which is relevant to the fatigue life for a stress amplitude of $\Delta \sigma_{i}$ in the $S-N$ curve of the fatigue test. When $D \geq 1$, the components are destroyed. The $S$ $N$ relationships of suspenders are obtained via a previously described fatigue test [33]:

$$
\Delta \sigma_{i}=12800 N_{i}^{0.27}
$$

where the unit of stress amplitude $\Delta \sigma_{i}$ is $\mathrm{MPa}$. After formula (3) is substituted into formula (2), formula (4) can be obtained:

$$
D=\sum_{i=1}^{k} \frac{n_{i}}{\left(\Delta \sigma_{i} / 12800\right)^{1 / 0.27}} .
$$

A stress cycle with variable amplitude is generally equivalent to that with constant amplitude. The equivalence principle states that the fatigue accumulation at constant amplitude with equivalent stress $D_{\mathrm{eq}}$ is the same as that with variable amplitude under the same load cycles; that is,

$$
D_{\mathrm{eq}}=\frac{\sum_{i=1}^{k} n_{i}}{N_{\mathrm{eq}}}=\sum_{i=1}^{k} \frac{n_{i}}{\left(\Delta \sigma_{i} / 12800\right)^{1 / 0.27}}
$$

where $N_{\text {eq }}$ is the relevant fatigue life for the equivalent stress amplitude $\Delta \sigma_{\text {eq }} . N_{\text {eq }}$ is solved using formula (5) and then substituted into formula (2). The calculated formula for the equivalent stress amplitude $\Delta \sigma_{i}$ can then be obtained as

$$
\Delta \sigma_{\mathrm{eq}}=\left(\frac{\left(\sum_{i=1}^{k} n_{i}\right)^{0.27}}{\sum_{i=1}^{k}\left(n_{i} / \Delta \sigma_{i}^{1 / 0.27}\right)}\right)^{0.27}
$$

\section{Results and Discussions}

The random traffic flows are simulated for 24 hours according to the method described above. To verify the characteristics of the random traffic flow produced according to the distribution of the actual traffic flow, statistical analyses are performed using sampling parameters for the random traffic flow over a period of 24 hours, including the headway, vehicle type ratio, and GVW of various vehicle types. Figure 13 shows the results of the statistical analyses, which demonstrate that the GVWs of various vehicle types in the random traffic flow all agreed with those of the actual traffic flow.

Figure 14 shows the stress process for Number 1 (shortest) and Number 10 (longest) suspenders under the random traffic flow, which demonstrates that the stress on Number 1 suspender varies in the range of $378-400 \mathrm{MPa}$ and that on Number 10 suspender varies in the range of $369-400 \mathrm{MPa}$. The difference in the minimum value for Number 1 and Number 10 suspenders is about $10 \mathrm{MPa}$, but the stress ranges have little difference.

The distribution of the stress amplitude is obtained based on a statistical analysis of the stress process, as shown in Figure 15. According to the statistical results, the stress amplitudes under the random traffic flow are very small, where the maximum stress amplitude is less than $24 \mathrm{MPa}$ for Number 1 suspender and the maximum stress amplitude is less than $30 \mathrm{MPa}$ for Number 10 suspender, while the $90 \%$ stress amplitude is less than $10 \mathrm{MPa}$.

According to formula (6), the equivalent stress amplitudes of the suspenders are calculated under variable amplitude loads. The equivalent stress amplitudes of various suspenders are shown in Figure 16. The equivalent stress amplitudes for 10 suspenders ranged from 7.41 to $9.65 \mathrm{MPa}$. In addition, the dead load stress is also shown in Figure 16; it can be seen that the live load stress amplitude is very small compared with the overall stress value and it only accounted for about $2 \%$ of the total stress. These results show that the fatigue damage to suspenders on the objective bridge is very low under the present vehicle loads.

It should be noted that this fatigue analysis is based on the current traffic levels. The traffic flow will increase with the service time of the bridge, while the fatigue performance of the steel wires in the suspenders may degenerate due to the corrosive environment. Thus, although the fatigue damage is low in the current conditions, they should be considered seriously during the later maintenance management of the bridge.

\section{Conclusions}

(1) In this study, 347 sensors are positioned in the SHMS of the objective bridge and the vehicle load acquisition equipment is embedded in the system to acquire the vehicle loads, as well as obtaining further information about the vehicles that passed over the observed section, such as the vehicle speed, direction, plate number, vehicle type, passing time, axle weight, and gross vehicle weight. This greatly improves the efficiency and accuracy of the traffic load survey.

(2) The traffic flow on the objective bridge mainly comprises ten types of truck (trucks accounted for $19.52 \%$ of the total traffic), where the gross vehicle weights of two-axle vehicles follow a third-order mixed log-normal distribution and those of three-axle, four-axle, five-axle, and six-axle 

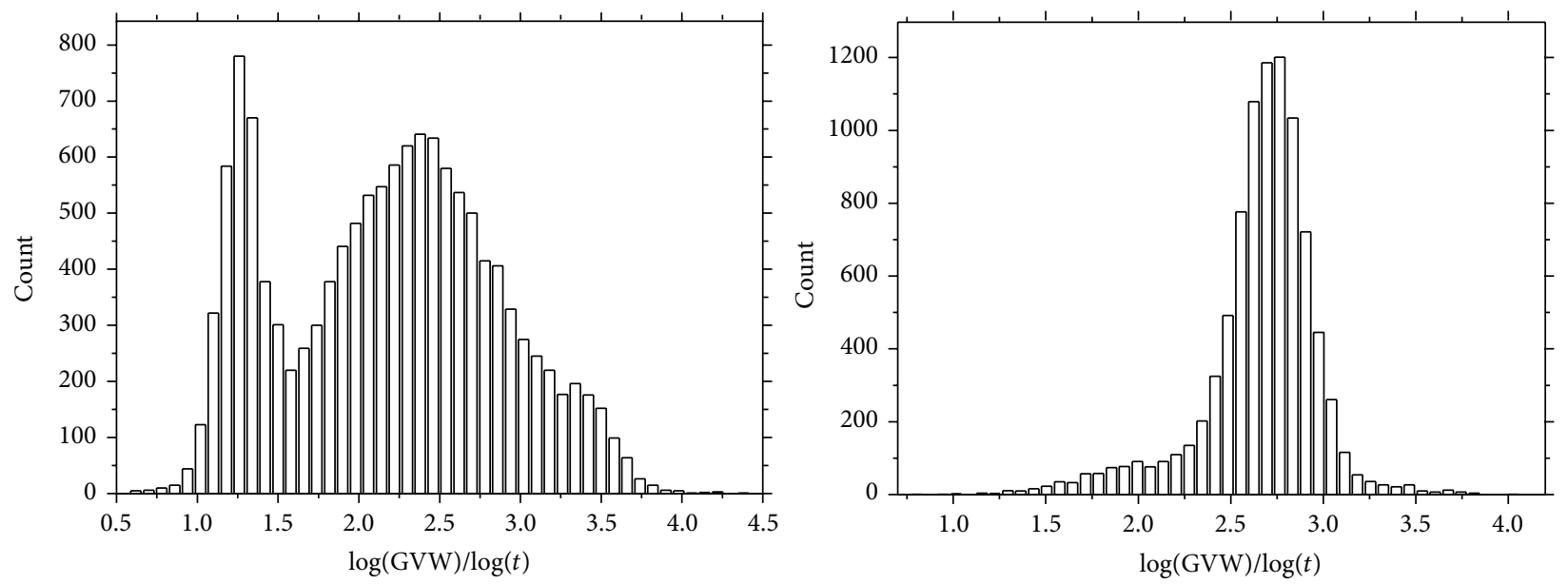

$\mathrm{V} 22$
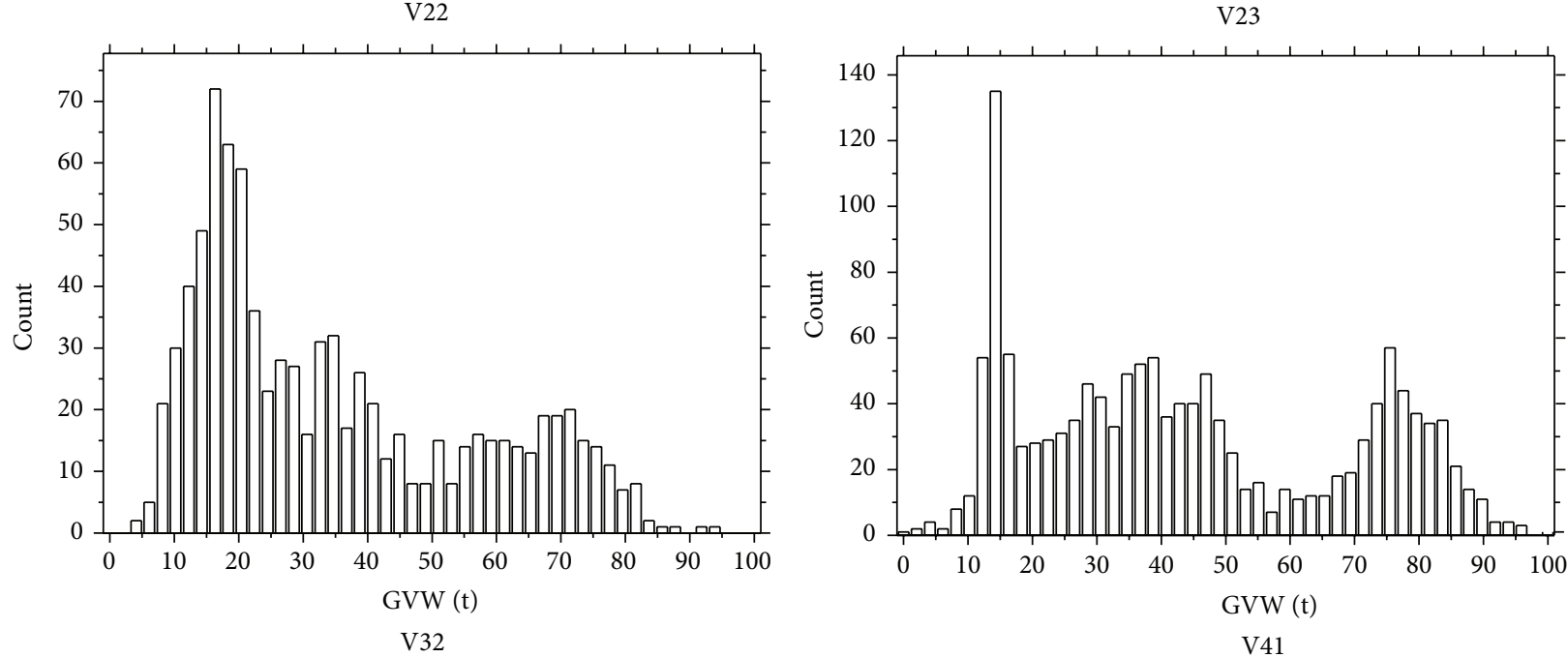

FIGURE 13: GVW probability distributions for simulated traffic flow.

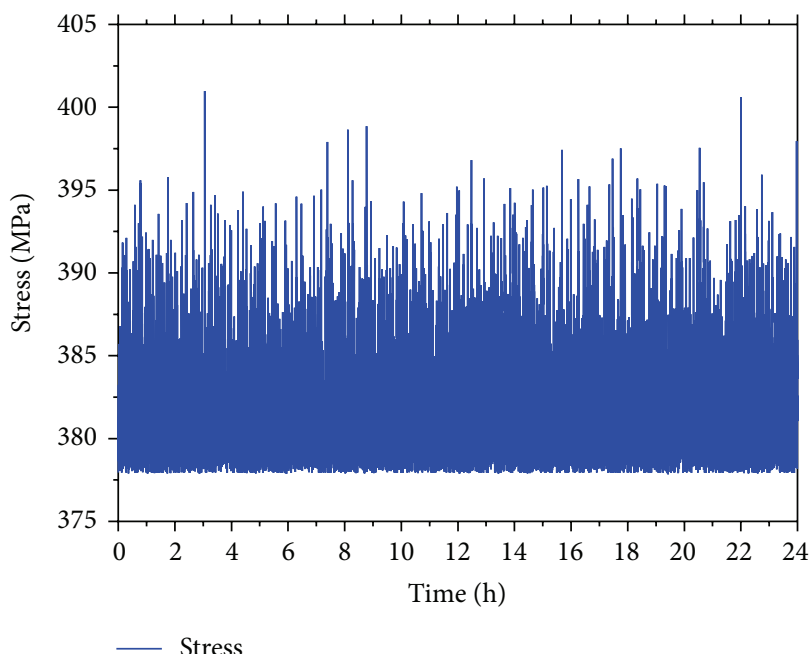

(a) Number 1

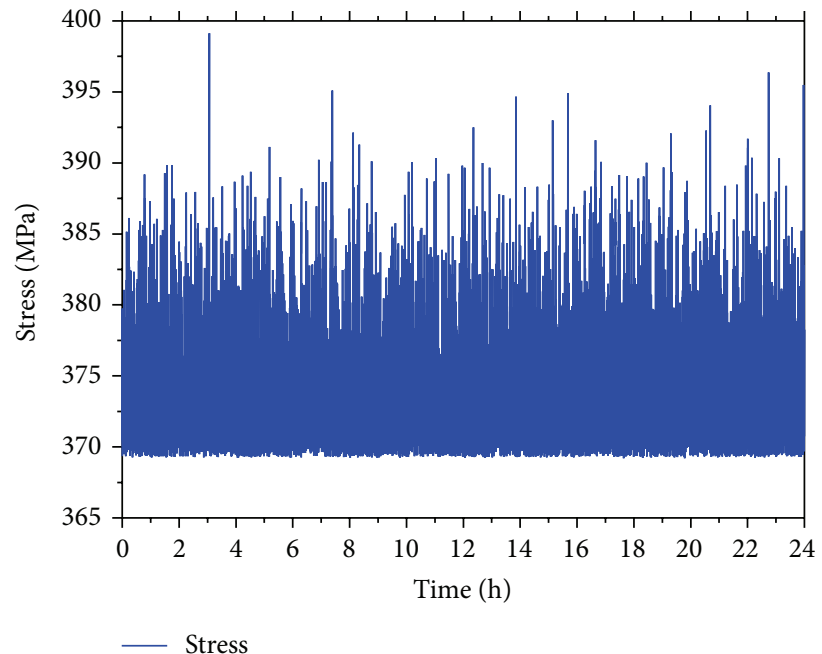

(b) Number 10

FIGURE 14: Stress processes for the suspenders. 


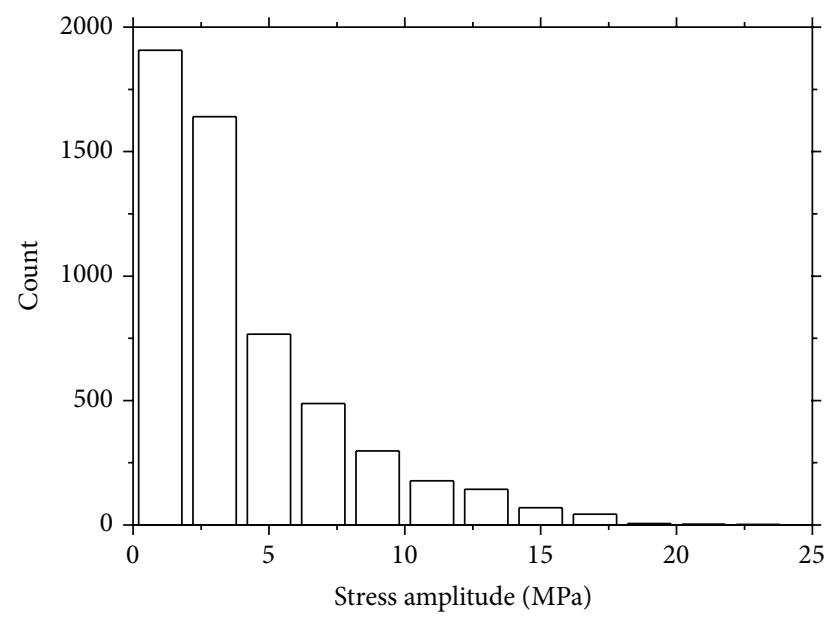

(a) Number 1 suspender

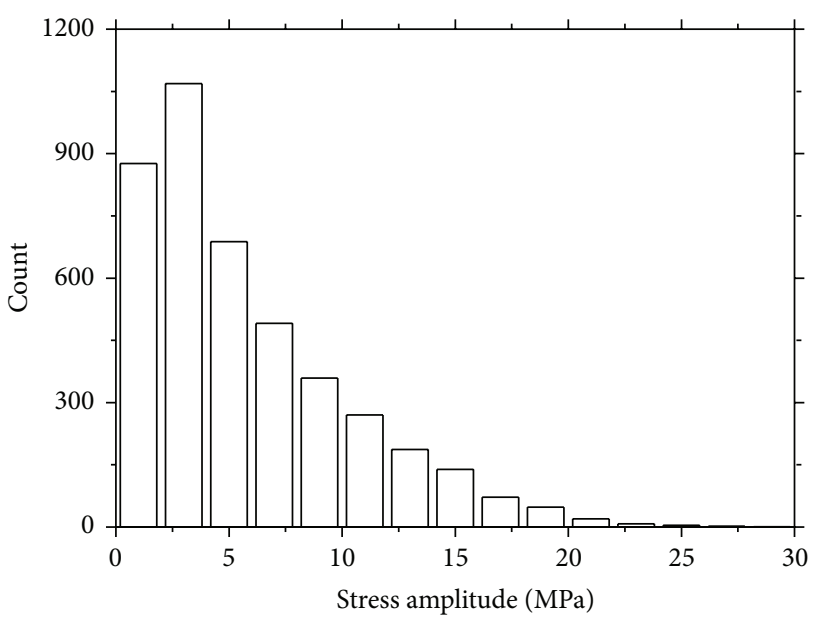

$\square$ Frequency

(b) Number 10 suspender

FIGURE 15: Statistical analysis of stress processes.

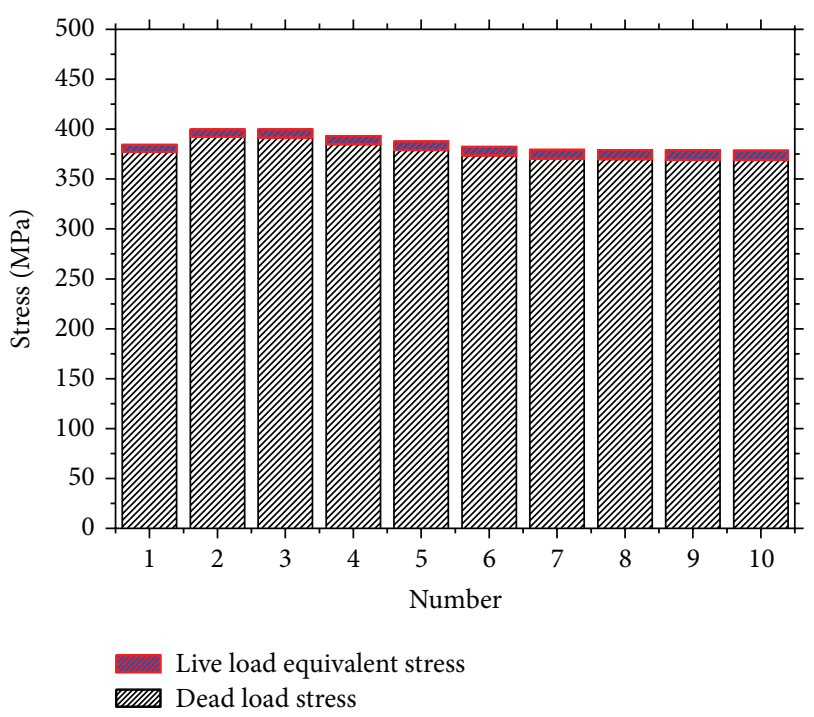

Figure 16: Equivalent stress of live load and dead load. vehicles follow a third-order mixed normal distribution. The gross vehicle weights of various vehicle types with different axle weights have a linear relationship. The headway of the following flow conforms to a log-normal distribution while that of the free flow has a Gamma distribution. The vehicle speed follows a normal distribution.

(3) Using the Monte Carlo method, the random traffic flow is simulated according to a statistical analysis of the data obtained. Based on the loading of the influence line in a random traffic flow, the stress spectrum is obtained according to the cyclic statistics of the stress process. The fatigue conditions of the bridge suspenders are analyzed according to the Palmgren-Miner linear fatigue cumulative damage criterion. The results show that the equivalent stress amplitude of the fatigue load due to vehicles is only 9.65 MPa, which accounts for about $2 \%$ of the total force, thereby demonstrating that the suspender fatigue damage is low under the current traffic load.

\section{Disclaimer}

The results and conclusions presented in this paper are those of the authors and they do not necessarily reflect the views of the sponsors.

\section{Conflict of Interests}

The authors declare that there is no conflict of interests regarding the publication of this paper.

\section{Acknowledgments}

This study was funded jointly by the Institute Basic Scientific Research Fund (Grant no. 2012A02) and the National Natural Science Foundation of China (NSFC) (Grant no. 51308510).

\section{References}

[1] W. Zhang, C. S. Cai, and F. Pan, "Nonlinear fatigue damage assessment of existing bridges considering progressively deteriorated road conditions," Engineering Structures, vol. 56, pp. 1922-1932, 2013.

[2] W. Zhang, Fatigue Performance of Existing Bridges under Dynamic Loads from Winds and Vehicles, Louisiana State University, Baton Rouge, La, USA, 2012.

[3] X. W. Ye, Y. H. Su, and J. P. Han, "A state-of-the-art review on fatigue life assessment of steel bridges," Mathematical Problems in Engineering, vol. 2014, Article ID 956473, 13 pages, 2014.

[4] B. Enright and E. J. O'Brien, "Monte Carlo simulation of extreme traffic loading on short and medium span bridges," Structure and Infrastructure Engineering, vol. 9, no. 12, pp. 12671282, 2013.

[5] E. J. OBrien and B. Enright, "Modeling same-direction two-lane traffic for bridge loading," Structural Safety, vol. 33, no. 4-5, pp. 296-304, 2011.

[6] C. C. Caprani, A. Lipari, and E. J. O’Brien, "Load effect of multilane traffic simulations on long-span bridges," in Proceedings of the 6th International Conference on Bridge Maintenance, 
Safety and Management (IABMAS '12), F. Biondini and D. M. Frangopol, Eds., pp. 1460-1467, July 2012.

[7] M. Gindy and H. H. Nassif, "Comparison of traffic load models based on simulation and measured data," in Proceedings of the Joint International Conference on Computing and Decision Making in Civil and Building Engineering, Montréal, Canada, June 2006.

[8] T. H. Yi, H. N. Li, and M. Gu, "Recent research and applications of GPS based technology for bridge health monitoring," Science China Technological Sciences, vol. 53, no. 10, pp. 2597-2610, 2010.

[9] T. H. Yi, H. N. Li, and M. Gu, "Optimal sensor placement for structural health monitoring based on multiple optimization strategies," The Structural Design of Tall and Special Buildings, vol. 20, no. 7, pp. 881-900, 2011.

[10] T.-H. Yi, H.-N. Li, and M. Gu, "Experimental assessment of high-rate GPS receivers for deformation monitoring of bridge," Measurement, vol. 46, no. 1, pp. 420-432, 2013.

[11] T. H. T. Chan, T. J. Miao, and D. B. Ashebo, "Statistical models from weigh-in-motion data," Structural Engineering and Mechanics, vol. 20, no. 1, pp. 85-110, 2005.

[12] X. Y. Zhou, Statistical Analysis of Traffic Loads and Their Effects on Bridges, University Paris-EST \& IFSTTAR, Paris, France, 2013.

[13] C. C. Caprani, Probabilistic Analysis of Highway Bridge Traffic Loading, National University of Ireland, University College Dublin, Dublin, Ireland, 2005.

[14] J. Zhao and T. Tabatabai, Analysis of Permit Vehicle Loads in Wisconsin, Wisconsin Highway Research Program, 2009.

[15] B. Chen, Z. Zhong, X. Xie, and P. Lu, "Measurement-based vehicle load model for urban expressway bridges," Mathematical Problems in Engineering, vol. 2014, Article ID 340896, 10 pages, 2014.

[16] E. J. Obrien and B. Enright, "Using weigh-in-motion data to determine aggressiveness of traffic for bridge loading," Journal of Bridge Engineering, vol. 18, no. 3, pp. 232-239, 2013.

[17] D. Hajializadeh, E. OBrien, B. Enright, E. Sheils, S. Wilson, and C. Caprani, "Probabilistic study of lifetime load effect distribution of bridges," in Proceedings of the 6th International ASRANet Conference for Integrating Structural Analysis, Croydon, UK, 2012.

[18] G. Fu and J. You, "Extrapolation for future maximum load statistics," Journal of Bridge Engineering, vol. 16, no. 4, pp. 527535, 2011.

[19] O.-S. Kwon, E. Kim, and S. Orton, "Calibration of live-load factor in LRFD bridge design specifications based on statespecific traffic environments," Journal of Bridge Engineering, vol. 16, no. 6, pp. 812-819, 2011.

[20] T. Guo, D. M. Frangopol, and Y. Chen, "Fatigue reliability assessment of steel bridge details integrating weigh-in-motion data and probabilistic finite element analysis," Computers \& Structures, vol. 112-113, pp. 245-257, 2012.

[21] C. Lan, H. Li, and J. Ou, "Traffic load modelling based on structural health monitoring data," Structure and Infrastructure Engineering, vol. 7, no. 5, pp. 379-386, 2011.

[22] Y. Q. Ni, X. W. Ye, and J. M. Ko, "Monitoring-based fatigue reliability assessment of steel bridges: analytical model and application," Journal of Structural Engineering, vol. 136, no. 12, pp. 1563-1573, 2010.

[23] E. J. Obrien, B. Enright, and A. Getachew, "Importance of the tail in truck weight modeling for bridge assessment," Journal of Bridge Engineering, vol. 15, no. 2, pp. 210-213, 2010.
[24] Y. Q. Ni, X. W. Ye, and J. M. Ko, "Modeling of stress spectrum using long-term monitoring data and finite mixture distributions," Journal of Engineering Mechanics, vol. 138, no. 2, pp. 175183, 2011.

[25] J. A. Prozzi and F. Hong, "Optimum statistical characterization of axle load spectra based on load-associated pavement damage," International Journal of Pavement Engineering, vol. 8, no. 4, pp. 323-330, 2007.

[26] S. Sriramula, D. Menon, and A. M. Prasad, "Axle load variations and vehicle growth projection models for safety assessment of transportation structures," Transport, vol. 22, no. 1, pp. 31-37, 2007.

[27] D. H. Timm, S. M. Tisdale, and R. E. Turochy, "Axle load spectra characterization by mixed distribution modeling," Journal of Transportation Engineering, vol. 131, no. 2, pp. 83-88, 2005.

[28] Ministry of Communications and Transportation (MOCAT), "General code for design of highway bridges and culverts," JTG D60-2004, Ministry of Communications and Transportation, Beijing, China, 2004.

[29] C. C. Caprani, E. J. O’Brien, and G. J. McLachlan, "Characteristic traffic load effects from a mixture of loading events on short to medium span bridges," Structural Safety, vol. 30, no. 5, pp. 394-404, 2008.

[30] E. J. OBrien, A. Hayrapetova, and C. Walsh, "The use of microsimulation for congested traffic load modeling of medium- and long-span bridges", Structure and Infrastructure Engineering, vol. 8, no. 3, pp. 269-276, 2012.

[31] C. C. Caprani, "Calibration of a congestion load model for highway bridges using traffic microsimulation," Structural Engineering International, vol. 22, no. 3, pp. 342-348, 2012.

[32] X. W. Ye, Y. Q. Ni, K. Y. Wong, and J. M. Ko, "Statistical analysis of stress spectra for fatigue life assessment of steel bridges with structural health monitoring data," Engineering Structures, vol. 45, pp. 166-176, 2012.

[33] K. Takena, C. Miki, H. Shimokawa, and K. Sakamoto, "Fatigue resistance of large-diameter cable for cable-stayed bridges," Journal of Sstructural Engineering, vol. 118, no. 3, pp. 701-715, 1992. 

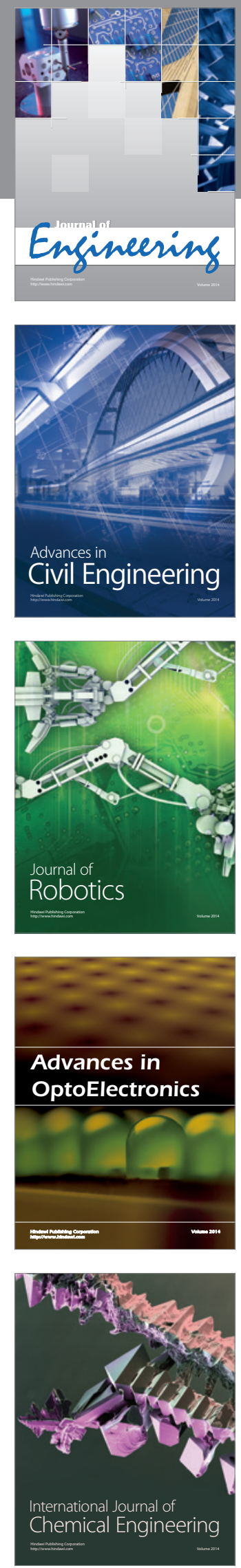

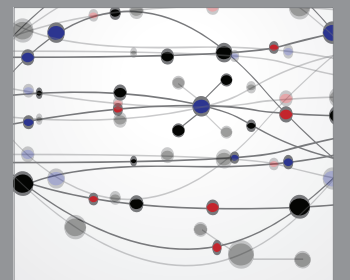

The Scientific World Journal
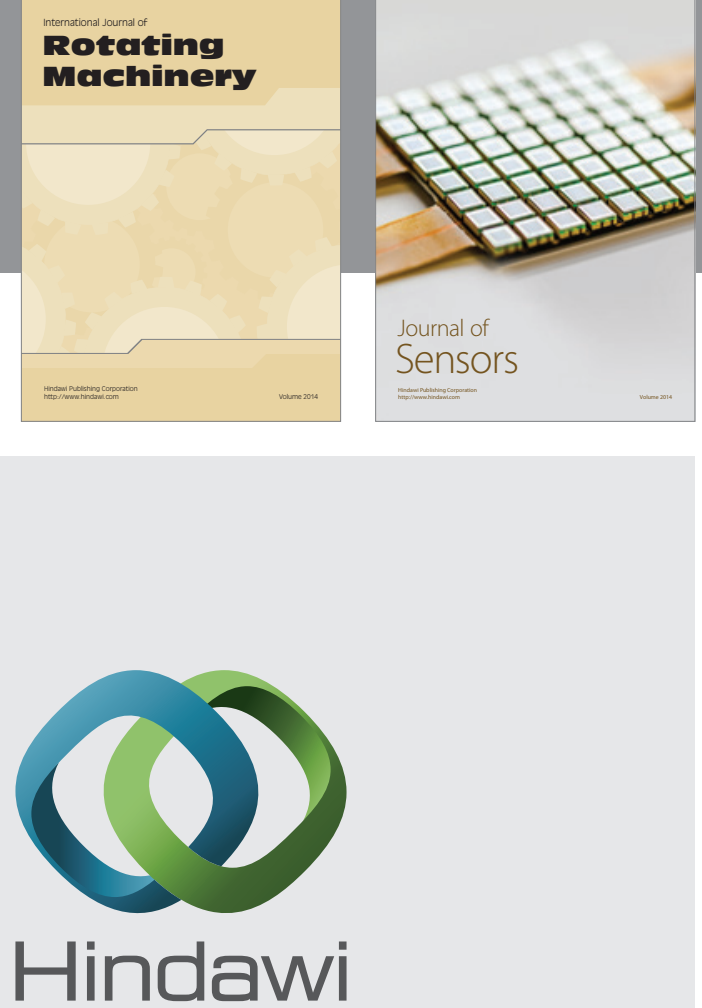

Submit your manuscripts at http://www.hindawi.com
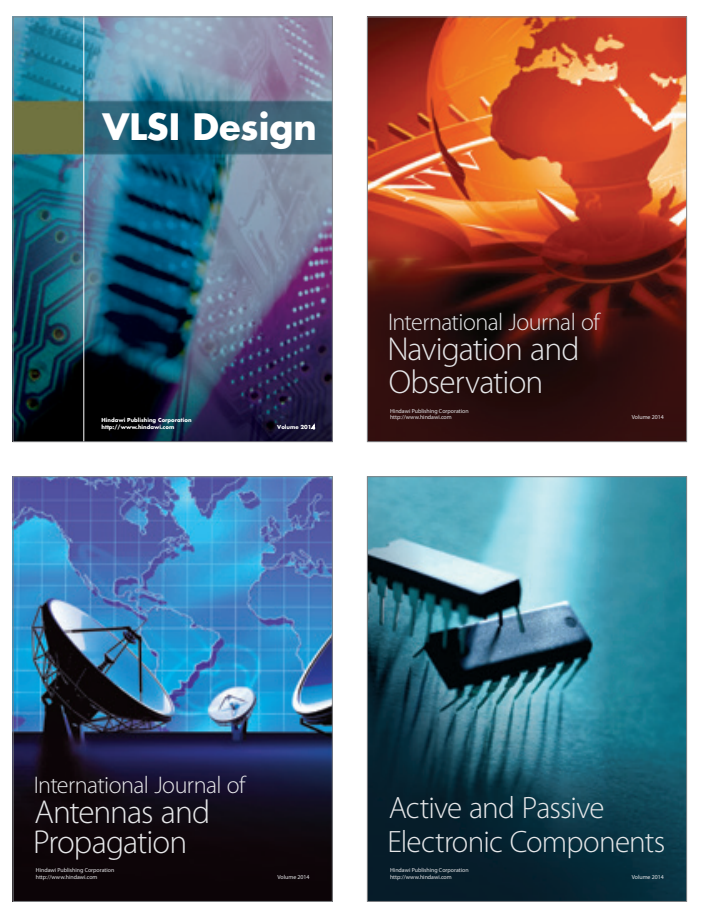
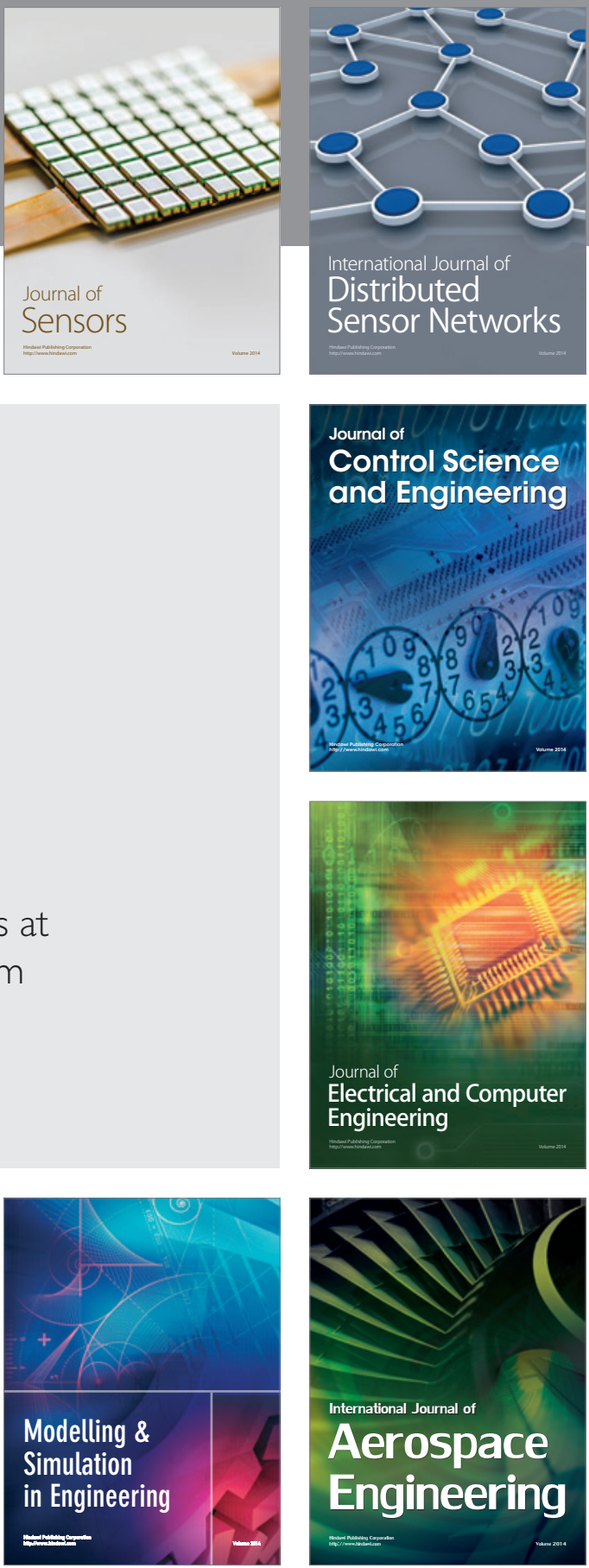

Journal of

Control Science

and Engineering
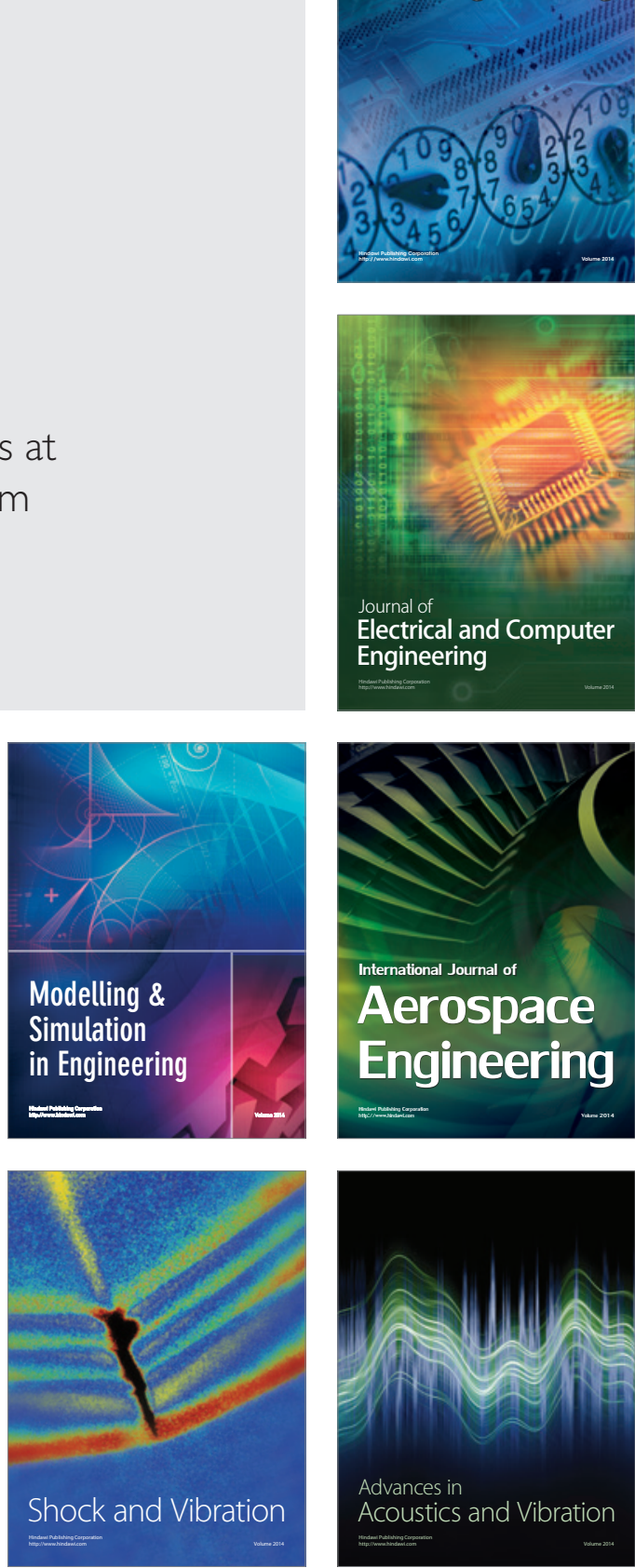